\title{
USING VIRTUAL REALITY TECHNOLOGY TO IMPROVE AIRCRAFT INSPECTION PERFORMANCE: PRESENCE AND PERFORMANCE MEASUREMENT STUDIES
}

\author{
Jeenal Vora, Santosh Nair, Anand K. Gramopadhye, Brian J. Melloy \\ Department of Industrial Engineering \\ Clems on University, SC \\ Eric Medlin, Andrew T. Duchowski \\ Department of Computer Science \\ Clems on University, SC \\ Barbara G. Kanki \\ NASA Ames Research Center
}

\begin{abstract}
Research in aircraft inspection and maintenance has revealed the criticality of human inspection performance in improving aviation safety. If we are to provide the general public with a safe and reliable air transportation system, inspection must be performed effectively, efficiently and consistently. Even though it is difficult to eliminate errors completely, continuing emphasis must be placed on identifying interventions to reduce errors and improve consistency in performance. Training has been identified as the primary intervention strategy in improving the quality and reliability of aircraft inspection performance. If training is to be successful, it is clear that we need to provide aircraft inspectors with tools to help enhance their inspection skills and improve performance. In response to this need a Virtual Reality (VR) based simulator was developed for visual inspection task of an aft cargo bay. Presence and performance validation studies were conducted to evaluate the simulator and are described as part of this paper.
\end{abstract}

\section{INTRODUCTION}

Aircraft inspection and maintenance are an essential part of a safe, reliable air transportation system. Training has been identified as the primary intervention strategy in improving inspection performance (Gramopadhye, et. al, 1998). If training is to be successful, it is clear that inspectors need to be provided with training tools to help enhance their inspection skills. Existing training for inspectors in the aircraft maintenance environment tends to be mostly on-the-job. Nevertheless, this may not be the best method of instruction (Gramopadhye et al., 1995; Latorella et al., 1992). For example, in OJT feedback may be infrequent, unmethodical, and/or delayed. Moreover, in certain instances feedback is economically prohibitive or infeasible due to the nature of the task. Thus, because the benefits of feedback in training have been well documented (e.g., Weiner, 1975), and for other reasons as well, alternatives to OJT are sought. Furthermore, training for improving visual inspection skills of aircraft inspectors is generally lacking at aircraft repair centers and aircraft maintenance facilities (FAA, 1991; FAA 1993). However, the application of training knowledge to enhance visual inspection skills has been well documented in the manufacturing industry. Training has been shown to improve the performance of both novice and experienced inspectors (Gramopadhye et al., 1995; Drury et al., 1991; W einer, 1975). Visual inspection skills can be taught effectively using representative photographic images showing a wide range of conditions with immediate feedback on the trainee's decision in a controlled environment (Blackmon, 1996). Using realis tic photographic images as a training aid in controlled practice with feedback has also been shown to be superior to only on- the-job training (OJT) (Gramopadhye et al., 1995; Latorella et al., 1992).

Thus, off-line training/retraining with feedback has a role to play in aircraft inspection training. One of the most viable approaches for delivering training given the many constraints and requirements imposed by the aircraft maintenance environment is computer-based training. Computer-based training offers several advantages relative to traditional training approaches; for example, computer-based training is more efficient, facilitates standardization, and supports distance learning. With computer technology becoming cheaper, the future will bring an increased application of advanced technology in training. Over the past decade, instructional technologists have offered numerous technology-based training devices with the promise of improved efficiency and effectiveness. These training devices are being applied to a variety of technical training applications. Examples of such technology include computerbased simulation, interactive videodiscs, and other derivatives of computer based applications. Compact disc read only memory (CD-ROM) and Digital Video Interactive (DVI) are two other technologies which will provide us with the "multimedia" training systems of the future. Many of these training delivery systems such as computer aided instruction, computer based multi-media training and intelligent tutoring systems are already being used today, thus ushering in a revolution in training.

In the domain of visual inspection, the earliest efforts to use computers for off-line inspection training were reported by Czaja and Drury, 1981. They used keyboard characters to develop a computer simulation of a visual inspection task. Other researchers to study inspection performance in a laboratory setting have also used similar simulations (e.g., 
McKernan 1989). Since these early efforts, Latorella et al., 1992 and Gramopadhye, Drury and Sharit, 1994 have used low fidelity inspection simulators using computer-generated images to develop off-line inspection training programs for inspection tasks. Similarly, Drury and Chi-Fen, (1995), studied human performance using a high fidelity computer simulation of a printed circuit board inspection. Another domain that has seen the application of advanced technology is that of inspection of x-rays for medical practice (e.g., Kundel et al, 1990). In summary, most of the work in the application of advanced technology to inspection training has focused on developing low fidelity simulators for running controlled studies in a laboratory environment (e.g., computer simulated line judgment task (Micalizzi and Goldberg, 1989). Thus, research efforts need to be extended in order to take full advantage of today' s computer technology.

In response, research efforts at the Training System Laboratory (TSL) at Clemson University have focussed on developing a computer-based inspection training programAutomated System of Instruction for Specialized Training (ASSIST), (Gramopadhye et al., 2000). The ASSIST program, developed using a task analytic methodology, features a PCbased inspection simulator wherein the entire airframe structure is divided into a series of images and a portion is presented for inspection. Despite its usefulness as a training tool for improving the inspection skills (Nickels et al, 2001), it has its limitations. The ASSIST simulator lacks realism because it uses only two-dimensional images of airframe structure. Moreover, neither does it provide a holistic view of the airframe structure nor does the inspector have the same experiences as when inspecting the actual aircraft. In response to this need, a high fidelity, immersive, realistic threedimensional Virtual Reality (VR) inspection simulator was developed at the Virtual Reality Eye Tracking (VRET) Laboratory at Clems on University.

If we are to propose the use of VR simulator for training, the VR environment must have the same look and feel as the real environment. Only then can we expect the effects of training to transfer from the VR environment to the real world. Virtual reality has been described by several researchers (Kalawsky, R.S, 1993; Burdea et al., 1994; Durlach et al., 1995; Heim M., 1998). The one most applicable to this research is that espoused by Cruz-Neira, (1993) who defines Virtual Reality as immersive, interactive, multisensory, viewer-centered, three-dimensional computer generated environments and the combination of technologies required to build these environments. The effectiveness of the virtual environments (VE' s) has often been linked to the sense of presence reported by users and has been measured using presence. Presence is defined as the subjective experience of being in one place or environment, even when one is physically situated in another (Singer et. al. 1996). This concept of experiencing presence as a normal awareness or attentional phenomenon is based on interaction between external stimuli and immersion factors. The involvement tendencies depend on focusing one's attention and energy on a coherent set of VE stimuli while the immersion tendencies perceive oneself as a part of the VE stimulus flow. According to Witmer and Singer (1998), both involvement and immersion are necessary conditions for experiencing presence. These same factors support the transition to or experience of presence in a remote or artificial environment and are used as bas is for presence questionnaire (PQ) to measure the degree of presence in VE's by soliciting the subjective opinion of humans for the applicability of the VR simulator to support training in the aircraft maintenance environment. The PQ ascertains the degree to which individuals experience presence in a VE and the influence of possible contributing factors on the intensity of this experience (Witmer et al., 1998). It is generally held that human performance in VEs is directly proportional to the degree of presence induced by the environment, which is in turn considered to be influenced by the individual's level of immersion in the VE (Witmer and Singer, 1998; Stanney et al., 1998).

If the VR environment is to be used as an offline tool for training, it is essential that the VR environment accurately mimic the real world environment (as perceived by the user/trainee). Moreover, if we are to collect data on human performance in VE for use in training, it is important that the data collected is accurate and valid. To address these issues two separate studies were conducted. The one on presence addressed the former and the performance validation study addressed the latter issue. This paper describes the VR environment and the two studies.

\section{THE VR SYSTEM - HARDWARE PLATFORM}

The primary rendering engine is a dual-rack, dualpipe, SGI Onyx ${ }^{\circledR}$ InfiniteReality ${ }^{\mathrm{TM}}$ system with 8 raster managers and 8 MIPS $®$ R $10000^{\mathrm{TM}}$ processors, each with $4 \mathrm{Mb}$ secondary cache. It is equipped with $3 \mathrm{~Gb}$ of main memory and $0.5 \mathrm{~Gb}$ of texture memory (Duchowski et al, 2000). Multimodal hardware components include a binocular ISCAN eye tracker mounted within a Virtual Research V8 (highresolution) Head Mounted Display (HMD). The V8 HMD offers $640 \times 480$ resolution per eye with separate left and right eye feeds. HMD position and orientation tracking is provided by an Ascension 6 Degree-Of-Freedom (6DOF) Flock Of Birds (FOB), a D.C. electromagnetic system with a $10 \mathrm{~ms}$ latency. A 6DOF tracked, hand-held mouse provides a means to represent a virtual tool for the user in the environment. Figure 1. shows the settings of the VR environment.
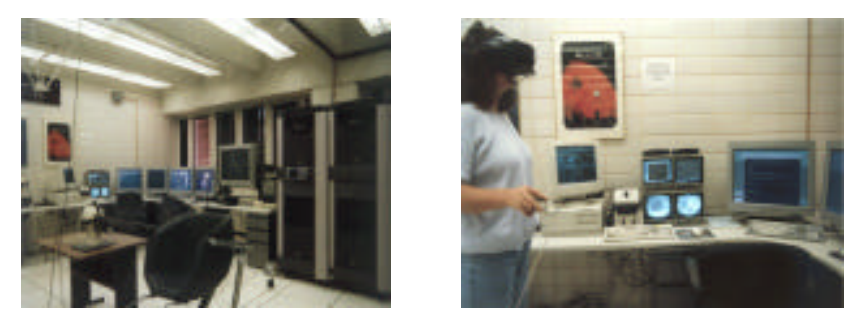

Figure 1. Virtual Reality Eye Tracking (VRET) Lab at Clemson University 


\section{DEVELOPMENT OF THE VR ENVIRONMENT}

The development of the VR environment was based on a detailed task analytic methodology (Duchowski et al, 2000). Data on aircraft inspection activity was collected through observation, interviewing, shadowing, and capturing digital record (using video and still images) techniques. More detail on the task description and task analytical methodology can be found in Duchowski, et al. (2000).

\section{Scenarios Developed}

Various scenarios were developed which were representative of those that would occur in the real world environment. A library of defects was developed occurring at various severity and locations. The following defects were modeled: corrosion, cracks and broken conduits. The representative defects are shown in Figure 2. By manipulating the type, severity, location and defect mix; experimenters can now create airframe structures that can be used for running controlled studies.
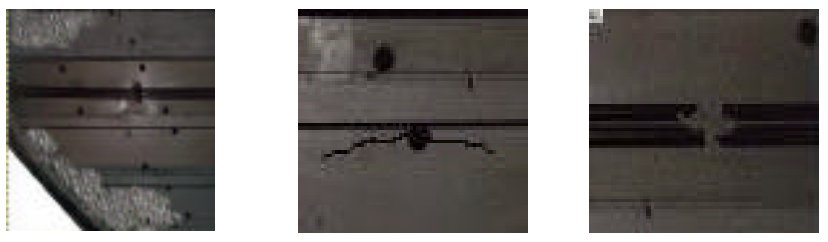

Figure 2. Sample Defects

\section{PRESENCE AND VALIDATION STUDIES}

Two separate sets of experiments were conducted in order to administer a broader vision of the applicability of the tool for off-line training inspection.

\section{Presence Study}

Objective. To measure the degree of presence of the VR simulator by subjective evaluation using the presence questionnaire (W itmer et al., 1998).

Subjects. Fourteen subjects between the ages of 20 to 30 years were randomly selected from a population of graduate and undergraduate students of Clemson University. Gallwey and Drury (1986) found that student subjects could be used in lieu of inspectors, as no significant differences exist between them and inspectors on simulated tasks. Subjects were screened for $20 / 20$ vision (corrected if necessary).

Experimental design. The study used a within subject design with the treatment factor of defects in the environment. There were four scenarios with defects and one with none. The experiment duration was limited to 30 minutes, the subjects being immersed in the VE for 25 minutes. The immersion duration was limited because of health and safety guidelines, which suggest that subjects should be immersed in a VE for no longer than 10-30 minutes (Stanney et al, 1998).

Procedure. Subjects were initially greeted and asked to sign the Informed Consent Form. Before commencing the experiment, they were taken to the hangar floor and shown the real aft cargo bin of a wide-bodied aircraft. They were then taken to the VR lab at Clemson University where the simulator was set up. Following this step, each subject was briefed on the experiment by reading a written description of the objectives of the study and the task. The researcher then answered to any of the subjects' questions.

Subjects were then allowed to practice with the virtual reality simulator and the 3-D mouse as part of software familiarization training. When the subjects were comfortable with it, they were randomly given the five scenarios with and without defects. The subjects had to walk through the environment, identify the defects present if any and use the 3D mouse to click on the defect and indicate their selection. After completing the scenarios, subjects were asked to complete the Presence Questionnaire (PQ).

Data on subjective evaluation was collected using the PQ questionnaire based on a 7-point likert scale with anchor at the midpoint. (W itmer et al., 1998).

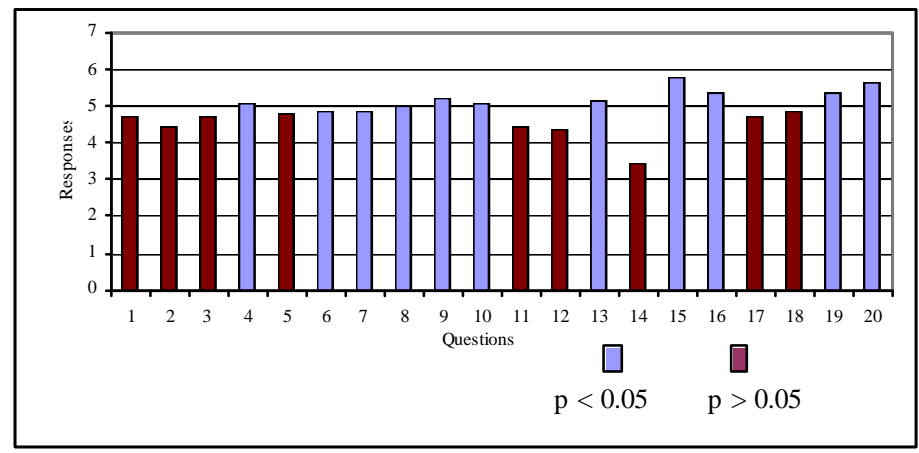

Figure 3. Mean Scores of Responses on Presence Questionnaire

Results and Discussion. The mean scores on the individual responses for the 20 questions of the questionnaire are shown in Figure 3. Wilcoxon test was conducted to see if the mean scores were significantly different. The results of the test are tabulated in Table 2. (Appendix A), with the column 3 showing whether the mean response was significantly different from the anchor value (4).

Analysis of the Wilcoxon test revealed that the system scored high on 11 of 20 questions. The results bode well for the level of presence experienced by the subjects. The high degree of presence as measured on some of the questions and the lack thereof on others are explained below.

The system scored high on the following presence related issues. The subjects experienced a high level of involvement in the VR environment (Questions 4, 6, 8, 9, 10 and 13). On issues like the visual aspects of the environment, sense of objects, anticipating the response of the system, surveying, experience in the VR environment contributed to the high sense of involvement. The VR system scored significantly high on the is sues related to the concentration on the assigned task by the subjects and also on the adjustment to the control devices, relating to a high level of realis $m$, which is a testament to the high quality of the interface (Questions 15, 16, 19 and 20). The most telling point was subject's response 
to Question 7, where in they indicated that the experiences with the VR environment were consistent with the real world experiences.

However the system did not show significant differences on is sues like close examination of the objects, viewing from multiple viewpoints, visual display quality and the interference on the control devices with the performance of the assigned task, suggesting that certain aspects of the interface need improvement (Questions 11, 12, 17 and 18). On the other hand, the subjects indicated that the interactions were not significantly natural (Questions 3 and 5) nor were they able to control the events (Question 1). This can be attributed to the fact that the subjects were not very familiar and comfortable using the control devices like the 3D mouse, walking around the simulator and identifying the defects correctly. In addition, the system was not very responsive to the actions initiated by the subjects (Questions 2 and 14). The main reason being that the simulator was operated on a Unix platform, which is a multi - user system, and the parallel processes running on it can significantly reduce the response time.

\section{Performance Measure Validation}

In the performance measure validation studies, visual search data was collected on separate measures of speed and accuracy. Speed measures were on visual search times, stopping times, incremental stopping time and total search time. Accuracy measures were the number of defects detected correctly, number of defects missed and number of false alarms. It is necessary for validating the results of the data collection method with some benchmark values. The benchmark values can be obtained by using the traditional way of collecting visual search performance data. This was achieved by conducting a pilot test run.

The objective of this study was to evaluate the validity of the performance measures displayed by the main simulator program with the data of performance measure found from traditional data collection technique.

The analysis of the results revealed that the program was giving accurate data and hence can be used for different performance measure studies in future. A minor difference of approximately 0.3 seconds was noted among the times from the two methods. This can be attributed to the fact that human reaction tends to be slower than the computer. Figure 8 shows a prototypical interface of the performance measure study.

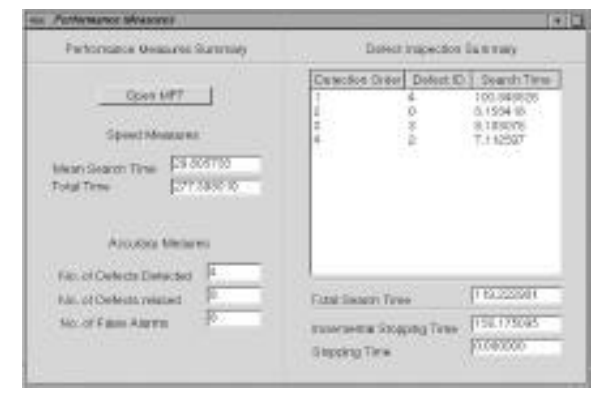

Figure 4. Performance Measure Interface

\section{CONCLUSIONS}

The VR system scored high on most aspects of presence and hence can be used as a training tool for visual inspection tasks. However, certain issues need to be addressed. The major concern being the delay in the system response experienced by the subjects in their task performance. This can be attributed to the fact that the VR system runs on a Unix based multi - user platform. Parallel users on the Unix platform had a significant impact on the speed with which the VR simulation ran and responded, hence causing the time lag. This can be avoided by setting priority levels to the works running on the Unix machine, by threading (Vinay. S, et.al, 2000) or by providing a dedicated CPU to the system.

\section{ACKNOWLEDGEMENTS}

This research was funded by grants to Dr. Gramopadhye, Dr. Duchowski and Dr. Melloy from NASA AMES Research Center (Program Manager: Barbara Kanki and from the Office of Aviation Medicine, Aviation Maintenance \& Inspection: Human Factors Research Program, Federal Aviation Administration (Program manager: Jean W ats on).

\section{REFERENCES}

1. Blackmon, R., and Gramopadhye, A.K. Using the Aircraft Inspector's Training System to Improve the Quality of Aircraft Inspection. In Proceedings of the 5th Industrial Engineering Research Conference (Minneapolis, MN, 1996), Institute of Industrial Engineers, pp. 447-451.

2. Czaja, S.J. and Drury, C.G., 1981, Training programs for inspection, Human Factors, 23(4): 473-484.

3. Drury, C. G. (1991). The maintenance technician in inspection. In Human Factors in Aviation Maintenance - Phase One Progress Report, DOT/FAA/AM-91/16, Washington, DC: Office of Aviation Medicine, pp. 45-103.

4. Drury, C. G., and Chi, C.F. (1995). A test of economic models of stopping policy in visual search. IIE Transactions, 382 -393.

5. Duchowski, A.T., Shivashankaraiah, V., Rawls, T., Gramopadhye, A.K., Melloy, B., Kanki, B. Binocular Eye Tracking in Virtual Reality for Inspection Training. In Eye Tracking Research \&Applications Symposium (Palm Beach Gardens, FL, 2000), ACM.

6. Duchowski, A. T. Course 05: Eye-Based Interaction in Graphical Systems: Theory \& Practice. ACM SIGGRA PH, New York, NY, July 2000. SIGGRAPH 2000 Course Notes. Available a http://www.vr.clemson.edu/eyetracking/sigcourse/ (last referenced 5/5/00).

7. Federal Aviation Administration (FAA), 1993. Human Factors in Aviation Maintenance - Phase Two Progress Report, DOT/FAA/AM-93/5, Office of Aviation Medicine, W ashington, D. C.

8. Federal Aviation Administration FAA. (1991). Human Factors in Aviation Maintenance - Phase OneProgress Report, DOT/FAA/AM-91/16, Washington, DC: Office of Aviation Medicine.

9. Foley, James D. and van Dam, Andries and Feiner, Steven K. and Hughes, John F., Computer Graphics: Principles and Practice, 2nd ed., Addis on-W esley, 1990, Reading, MA

10. Gramopadhye, A., Drury, C., and Sharit, J. (1994) Training for Decision Making in Aircraft Inspection. Proceedings of the Human Factors and Ergonomics Society 37th Annual Meeting, 1267-1272. Seattle, W A. 
11. Gramopadhye, A.K., Ivaturi, S., Blackmon, R.B., and Kraus, D. C. (1995). Teams and teamwork: Implications for team training within the aircraft inspection and maintenance environment, FAA1995 Technical Report. Office of Aviation Medicine. FAA.

12. Gramopadhye, S. Bhagwat, D. Kimbler, and J. Greenstein. The Use of Advanced Technology for Visual Inspection Training. Applied Ergonomics, 29(5):361-375, 1998.

13. Gramopadhye, A.K., Melloy, B.J., Chen, S., Bingham, J. Use of Computer Based Training for Aircraft Inspectors: Findings and Recommendations. In Proceedings of the HFES/IEA Annual Meeting (San Diego, CA, August 2000).

14. Kundel. H., Nodine, C., and Krupinski, E. Computer displayed eye position as a visual aid to pulmonary nodule interpretation. Investigative Radiology, 25, 1990, pp. 890-896.

15. Latorella, K.A., Gramopadhye, A. K., Prabhu, P. V., Drury, C.G., Smith, M. A., and Shanahan, D. E. (1992). Computer-simulated aircraft inspection tasks for off-line experimentation. In Proceedings of the Human Factors Society $36^{\text {th }}$ Annual Meeting, pp. 92-96. Santa Monica, CA: The Human Factors Society.

16. McKernan, K. 1989 The benefits of prior information on visual search for multiple faults. Unpublished Master's Thesis. State University of New York at Buffalo.

17. Micalizzi, J. and Goldberg, J., 1989, Knowledge of results in visual inspection decision: sensitivity or criterion effect. International Journal of Industrial Ergonomics, 4, pp. 225-235.
18. Nickles, G., Marshall, J., Gramopadhye, A. K. and Melloy, B. ASSIST: Training Program for Inspectors in the Aircraft Maintenance Industry. International Encyclopedia for Ergonomics and Human Factors. Taylor and Francis - UK (Invited Chapter), Vol. 2., 1178 1180, ISBN: 0748408487,2001.

19. Singer, M.J., Witmer, B.G. (1996). Presence Measures for Virtual Environments: Background \& Development. Draft United States Army Research Institute for the Behavioral and Social Sciences.

20. Stanney, K.M., Mourant, R.R., Kennedy,R.S (1998). Human Factor Issues in Virtual Environments: A Review of the Literature. Presence 7, 4, pp.327-351.

21. Weiner, E. (1975) Individual and group differences in inspection, Human Reliability in Quality Control. by C. Drury and J. Fox (Eds). Taylor and Francis. London.

22. Witmer, B.G., and Singer, M.J. (1998). Measuring Presence in Virtual Environments: A Presence Questionnaire. Presence 7, 3, pp. 225-240.

\section{Appendix A}

Table 2. Results of Wilcoxon Test.

\begin{tabular}{|c|c|c|}
\hline Question \# & Mean (S.D.) & $\begin{array}{c}\text { Wilcoxon } \\
\text { Test }\end{array}$ \\
\hline 1. How much were you able to control events? & $4.71(1.07)$ & $(\mathrm{p}>0.05)$ \\
\hline $\begin{array}{l}\text { 2. How responsive was the environment to actions that you initiated (or } \\
\text { performed)? }\end{array}$ & $4.43(1.02)$ & $(\mathrm{p}>0.05)$ \\
\hline 3. How natural did your interactions with the environment seem? & $4.71(1.64)$ & $(\mathrm{p}>0.05)$ \\
\hline 4. How much did the visual aspects of the environment involve you? & $5.07(1.49)$ & $(\mathrm{p}<0.05)$ \\
\hline $\begin{array}{l}\text { 5. How natural was the mechanism which controlled movement through } \\
\text { the environment? }\end{array}$ & $4.79(1.53)$ & $(\mathrm{p}>0.05)$ \\
\hline 6. How compelling was your sense of objects moving through space? & $4.86(0.95)$ & $(\mathrm{p}<0.05)$ \\
\hline $\begin{array}{l}\text { 7. How much did your experiences in the virtual environment seem } \\
\text { consistent with vour real world experiences? }\end{array}$ & $4.86(0.95)$ & $(\mathrm{p}<0.05)$ \\
\hline $\begin{array}{l}\text { 8. Were you able to anticipate what would happen next in response to } \\
\text { the actions that you performed? }\end{array}$ & $5(1.04)$ & $(\mathrm{p}<0.05)$ \\
\hline $\begin{array}{l}\text { 9. How completely were you able to actively survey or search the } \\
\text { environment using vision? }\end{array}$ & $5.21(1.25)$ & $(\mathrm{p}<0.05)$ \\
\hline $\begin{array}{l}\text { 10. How compelling was your sense of moving around inside the virtual } \\
\text { environment? }\end{array}$ & $5.07(1.44)$ & $(\mathrm{p}<0.05)$ \\
\hline 11. How closely were you able to examine objects? & $4.43(1.4)$ & $(\mathrm{p}>0.05)$ \\
\hline 12. How well could you examine objects from multiple viewpoints? & $4.36(1.08)$ & $(\mathrm{p}>0.05)$ \\
\hline 13. How involved were you in the virtual environment experience? & $5.14(1.1)$ & $(\mathrm{p}<0.05)$ \\
\hline $\begin{array}{l}\text { 14. How much delay did you experience between your actions and } \\
\text { expected outcomes? }\end{array}$ & $3.43(1.22)$ & $(\mathrm{p}>0.05)$ \\
\hline 15. How quickly did you adjust to the virtual environment experience? & $5.79(0.89)$ & $(\mathrm{p}<0.05)$ \\
\hline $\begin{array}{l}\text { 16. How proficient in moving and interacting with the virtual } \\
\text { environment did vou feel at the end of the experience? }\end{array}$ & $5.36(0.93)$ & $(\mathrm{p}<0.05)$ \\
\hline $\begin{array}{l}\text { 17. How much did the visual display quality interfere or distract you } \\
\text { from performing assigned tasks or required activities? }\end{array}$ & $4.71(1.54)$ & $(\mathrm{p}>0.05)$ \\
\hline $\begin{array}{l}\text { 18. How much did the control devices interfere with the performance of } \\
\text { assigned tasks or with other activities? }\end{array}$ & $4.86(1.56)$ & $(\mathrm{p}>0.05)$ \\
\hline $\begin{array}{l}\text { 19. How well could you concentrate on the assigned tasks or required } \\
\text { activities rather than on the mechanisms used to perform those tasks or } \\
\text { activities? }\end{array}$ & $5.36(1.5)$ & $(\mathrm{p}<0.05)$ \\
\hline $\begin{array}{l}\text { 20. How easily did you adjust to the control devices used to interact } \\
\text { with the virtualenvironment? }\end{array}$ & $5.64(1.5)$ & $(\mathrm{p}<0.05)$ \\
\hline
\end{tabular}

